Article

www.mdpi.com/journal/molecules

\title{
Mn(III)-Initiated Facile Oxygenation of Heterocyclic 1,3-Dicarbonyl Compounds
}

\author{
Md. Taifur Rahman, Md. Aminul Haque, Hikaru Igarashi and Hiroshi Nishino * \\ Department of Chemistry, Graduate School of Science and Technology, Kumamoto University, \\ Kurokami 2-39-1, Kumamoto 860-8555, Japan \\ * Author to whom correspondence should be addressed; E-Mail: nishino@sci.kumamoto-u.ac.jp; \\ Tel.: +81-96-342-3374; Fax: +81-96-342-3374.
}

Received: 27 September 2011; in revised form: 7 November 2011 / Accepted: 9 November 2011 / Published: 16 November 2011

\begin{abstract}
The Mn(III)-initiated aerobic oxidation of heterocyclic 1,3-dicarbonyl compounds, such as 4-alkyl-1,2-diphenylpyrazolidine-3,5-diones, 1,3-dialkylpyrrolidine2,4-diones, 3-alkyl-1,5-dimethylbarbituric acids, and 3-butyl-4-hydroxy-2-quinolinone gave excellent to good yields of the corresponding hydroperoxides, which were gradually degraded by exposure to the metal initiator after the reaction to afford the corresponding alcohols. The synthesis of 30 heterocyclic 1,3-dicarbonyl compounds, the corresponding hydroperoxides and the 10 alcohols, their characterization, and the limitations of the procedure are described. In addition, the mechanism of the hydroperoxidation and the redox decomposition of the hydroperoxides are discussed.
\end{abstract}

Keywords: hydroperoxides; peroxy radicals; aerobic oxidation; redox; 2-hydroxy-1,3dicarbonyl compounds

\section{Introduction}

Oxygenation of enolates has been considered as an important organic transformation [1-3], because the $\alpha$-hydroxycarbonyl moiety is used as a starting material or an intermediate for the synthesis of some natural products [4-8]. In particular, the 2-hydroxy-1,3-dicarbonyl moiety can be found in biologically important compounds such as indole alkaloids, e.g., vindorosine and vindoline [9-12], the cyclopentenoid kjellamanianone [13], and tetracycline-type antibiotics such as doxycycline [14,15]. 4-Butyl-1,2-diphenylpyrazolidine-3,5-dione (phenylbutazone), a nonstereoidal drug, is an efficient 
reducing cofactor for the peroxidase activity of prostaglandin $H$ synthase [16,17]. Phenylbutazone inhibits the production of lipid mediators causing inflammation but paradoxically performs this via the intermediacy of the peroxy radical and hydroperoxide, which may themselves be proinflammatory. 4-Hydroperoxyphenylbutazone shows a significantly stronger cardiodepressive and coronary constricting effects compared to phenylbutazone itself, 4-hydroxyphenylbutazone, and the ring-opened decomposition product of the hydroperoxide [18]. These phenomena could shed light on the significance of the 4-hydroperoxyphenylbutazone regarding the antiinflammatory or other biological activities of phenylbutazone $[19,20]$ and could explain the side effects such as gastric irritation and toxicity associated with phenylbutazone. Although many reagents have been utilized for the introduction of an oxygen functionality at the 2-position of 1,3-dicarbonyl compounds, the hydroxyl functionality could be introduced at the $\alpha$-position in most of the cases [21-30].

In connection with our current investigation of the $\mathrm{Mn}(\mathrm{OAc})_{3}$-assisted aerobic oxidation [31-36], we found the double hydroperoxyalkylaton of barbituric acids [37], pyrazolidine-3,5-diones (Scheme 1) [38,39], 4-hydroxy-1H-quinolin-2-ones [40], and tetronic acid [41]. The reaction could not be stopped at the monohydroperoxyalkylation stage.

Scheme 1. Mn(III)-assisted aerobic oxidation of 1,2-diphenylpyrazolidine-3,5-dione $(\mathrm{R}=\mathrm{H})$ [38-39] and phenylbutazone $(\mathrm{R}=\mathrm{Bu})$ [42].

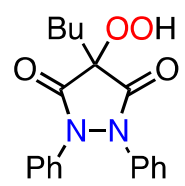

$(99 \%)$

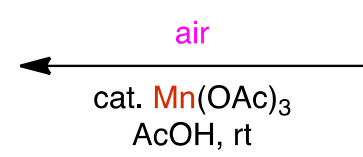

$(\mathrm{R}=\mathrm{Bu})$ Phenylbutazone
"current work"

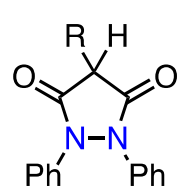

$(\mathrm{R}=\mathrm{H})$
1,2-Diphenylpyrazolidine-3,5-dione

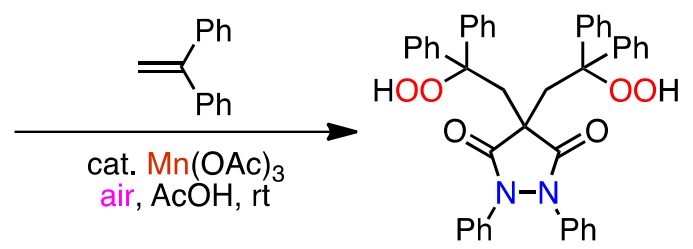

$(96 \%)$

Surprisingly, when phenylbutazone was treated under similar reaction conditions in the absence of an alkene, direct hydroperoxidation occurred and the corresponding solid 4-hydroperoxyphenylbutazone was produced quantitatively (Scheme 1) [42]. We foresaw that the reaction could be very useful for the synthesis of hydroperoxides under very mild aerobic oxidation conditions. Therefore, in order to examine the applicability of $\mathrm{Mn}(\mathrm{OAc})_{3}$-assisted $\alpha$-hydroperoxidation, biologically important heterocyclic 1,3-dicarbonyl compounds, e.g., 1,3-dialkylpyrrolidine-2,4-diones 3, 3-alkyl-1,5-dimethylbarbituric acids 5, and 3-butyl-4-hydroxy-2-quinolinone (7) as well as various 4-monoalkyl-substituted pyrazolidine-3,5-diones 1 were subjected to the reaction, and we obtained very similar results, whereby the corresponding hydroperoxides were obtained in excellent to good yields. In this paper, the full results of the earlier work [42], applications and limitations of the $\mathrm{Mn}(\mathrm{III})$-initiated direct $\alpha$-hydroperoxidation, and the related reactions are described. Specifically, the full characterization of all the starting materials $\mathbf{1}, \mathbf{5}$, and 7 , and all the hydroperoxides published in the reference [42], the full results of the hydroperoxidation of 1,3-dialkylpyrrolidine-2,4-diones 3, including the characterization of the corresponding hydroperoxides, and the mechanism of the $\mathrm{Mn}$ (III)-initiated autoxidation are discussed. In addition, the limitations of the hydroperoxidation are mentioned using the reaction of acyclic amides, cyclic ketones and esters as model, and the synthesis of 2-hydroxy-1,3-dicarbonyl compounds using the reduction of the hydroperoxides is described. 


\section{Results and Discussion}

\subsection{Aerobic Oxidation of 4-Alkyl-substituted Pyrazolidine-3,5-diones 1a-h}

4-Alkyl-1,2-diphenylpyrazolidine-3,5-diones 1a-h were prepared by a simple condensation reaction between the corresponding alkyl malonate and 1,2-diphenylhydrazine in the presence of $\mathrm{NaH}$ in boiling chlorobenzene [17]. With the pyrazolidinediones $\mathbf{1 a}-\mathbf{h}$ in hand, a mixture of phenylbutazone (1e, $1 \mathrm{mmol})$ and $\mathrm{Mn}(\mathrm{OAc})_{3}(0.1 \mathrm{mmol})$ in glacial $\mathrm{AcOH}(30 \mathrm{~mL})$ was stirred at $23{ }^{\circ} \mathrm{C}$ under an aerobic atmosphere, and the desired 4-hydroperoxypyrazolidinedione $2 \mathrm{e}$ was produced in quantitative yield (Scheme 2 and Table 1, entry 9). To scrutinize the role of $\mathrm{Mn}(\mathrm{OAc})_{3}$ in the aerobic oxidation, we carried out some reactions of 4-i-propypyrazolidinedione $1 \mathbf{d}$ under different reaction conditions. When the pyrazolidinedione $1 \mathbf{d}$ was stirred in the absence of $\mathrm{Mn}(\mathrm{OAc})_{3}$, no conversion to the hydroperoxide 2d was observed (entry 4). Using $\mathrm{Cu}(\mathrm{OAc})_{2}$ and ammonium cerium(IV) nitrate (CAN) as the catalyst was not effective in the autoxidation (entries 5 and 6). Therefore, it could be inferred that $\mathrm{Mn}(\mathrm{OAc})_{3}$ was essential for the hydroperoxidation and that the reaction is neither thermal nor it is induced by sunlight or visible light. While carrying out the reaction of $\mathbf{1 d}$ in the presence or absence of light (entries 7 and 8), there is no alteration in the yield of the hydroperoxide $\mathbf{2 d}$. Thus, the reaction is not light-assisted. Various alkyl groups were used as the substituent at the 4-position of the pyrazolidinedione, but in all cases similar quantitative conversion to the corresponding hydroperoxides was observed. The results are summarized in Table 1.

Scheme 2. Autoxidation of 4-alkyl-substituted 1,2-diphenylpyrazolidine-3,5-diones 1a-h.
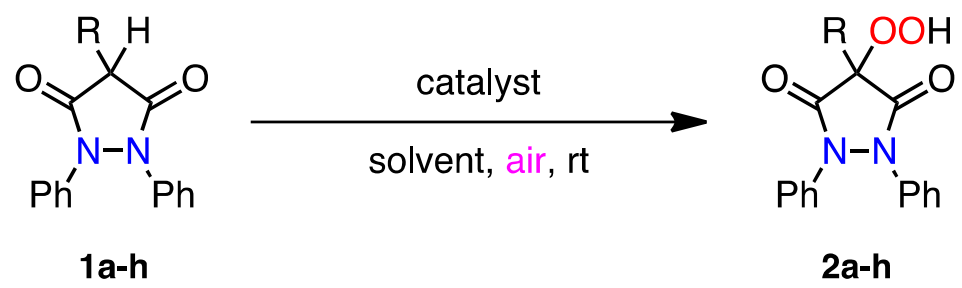

$$
\begin{array}{ll}
\mathbf{a}: R=M e & \text { e }: R=B u \\
\mathbf{b}: R=E t & \mathbf{f}: R=t-B u \\
\mathbf{c}: R=\operatorname{Pr} & \mathbf{g}: R=B n \\
\mathbf{d}: R=i-\operatorname{Pr} & \mathbf{h}: R=\text { Cyclopentyl }
\end{array}
$$

\begin{tabular}{|c|c|c|c|c|c|}
\hline Entry & 1 & Oxidant & 1:oxidant ${ }^{b}$ & Time/h & Product/yield (\%) \\
\hline 1 & 1a & $\mathrm{Mn}(\mathrm{OAc})_{3}$ & $1: 0.1$ & 2 & $\mathbf{2 a}(95)$ \\
\hline 2 & $1 b$ & $\mathrm{Mn}(\mathrm{OAc})_{3}$ & 1:0.1 & 2 & $\mathbf{2 b}(95)$ \\
\hline 3 & 1c & $\mathrm{Mn}(\mathrm{OAc})_{3}$ & 1:0.1 & 2 & 2c (99) \\
\hline 4 & 1d & none & - & 3 & Recovery of 1d (100) \\
\hline 5 & 1d & $\mathrm{Cu}(\mathrm{OAc})_{2}$ & 1:0.2 & 15 & Recovery of 1d (94) \\
\hline $6^{\mathrm{d}}$ & 1d & $\mathrm{CAN}^{\mathrm{e}}$ & 1:0.1 & 1 & $\mathbf{2 d}(40)$ \\
\hline 7 & 1d & $\mathrm{Mn}(\mathrm{OAc})_{3}$ & 1:0.1 & 2 & 2d (97) \\
\hline
\end{tabular}

Table 1. Aerobic oxidation of 4-alkyl-substituted pyrazolidinediones $\mathbf{1 a}-\mathbf{h}$ in the presence of a metal oxidant ${ }^{\mathrm{a}}$. 
Table 1. Cont.

\begin{tabular}{cccccc}
\hline Entry & $\mathbf{1}$ & Oxidant & 1:oxidant $^{\mathbf{b}}$ & Time $/ \mathbf{h}$ & Product/yield (\%) $^{\mathbf{c}}$ \\
\hline $8^{\mathrm{f}}$ & $\mathbf{1 d}$ & $\mathrm{Mn}(\mathrm{OAc})_{3}$ & $1: 0.1$ & 2 & $\mathbf{2 d}(96)$ \\
9 & $\mathbf{1 e}$ & $\mathrm{Mn}(\mathrm{OAc})_{3}$ & $1: 0.1$ & 2 & $\mathbf{2 e}(99)$ \\
10 & $\mathbf{1 f}$ & $\mathrm{Mn}(\mathrm{OAc})_{3}$ & $1: 0.1$ & $10 \mathrm{~min}$ & $\mathbf{2 f}(95)$ \\
11 & $\mathbf{1 g}$ & $\mathrm{Mn}(\mathrm{OAc})_{3}$ & $1: 0.1$ & 2 & $\mathbf{2 g}(97)$ \\
12 & $\mathbf{1 h}$ & $\mathrm{Mn}(\mathrm{OAc})_{3}$ & $1: 0.1$ & 2 & $\mathbf{2 h}(99)$ \\
\hline
\end{tabular}

${ }^{a}$ The reaction of $\mathbf{1}(1 \mathrm{mmol})$ was carried out in $\mathrm{AcOH}$ at ambient temperature in air; ${ }^{\mathrm{b}}$ Molar ratio;

${ }^{\mathrm{c}}$ Isolated yield is based on the pyrazolidinedione $\mathbf{1}$ used; ${ }^{\mathrm{d}}$ The reaction was carried out in $\mathrm{MeOH}$ at $0{ }^{\circ} \mathrm{C} ;{ }^{\mathrm{e}}$ Ammonium cerium(IV) nitrate; ${ }^{\mathrm{f}}$ The reaction was carried out in the dark.

\subsection{Aerobic Oxidation of 3-Alkyl-substituted Pyrrolidine-2,4-diones 3a-p}

We were pleased to confirm that the specific hydroperoxidation succeeded using pyrazolidinediones $\mathbf{1 a}-\mathbf{h}$, so we next applied the reaction to 1,3-dialkyl-substituted pyrrolidine-2,4-diones $\mathbf{3 a}-\mathbf{p}$ which are structurally similar to the pyrazolidinediones. The pyrrolidine-2,4-diones $\mathbf{3 a}-\mathbf{p}$ were prepared by the Dieckmann condensation of $N$-alkanoyl- $N$-alkylglycinates which were produced by the reaction of $\alpha$-bromoacetate with alkylamines followed by alkanoylation with the corresponding alkanoyl chloride (see Experimental section) [43-47]. The 2,4-pyrrolidinediones 3a-p exist as an enol form (3-alkyl-4hydroxy-3-pyrrolin-2-ones) in an aprotic polar solvent, such as DMSO- $d_{6}$ [48]. With the 2,4-pyrrolidinediones 3a-p in hand, we first explored the hydroperoxidation of 3a. When the reaction was carried out using a stoichiometric amount of $\mathrm{Mn}(\mathrm{OAc})_{3}$, the oxidant was consumed after $2 \mathrm{~h}$, and the desired hydroperoxide $4 \mathbf{a}$ was obtained in 65\% yield (Scheme 3 and Table 2, entry 1).

Scheme 3. Aerobic oxidation of 1,3-dialkyl-substituted pyrrolidine-2,4-diones 3a-p.<smiles>[R]C1=C(O)CN([R7])C1=O</smiles>

3a-p

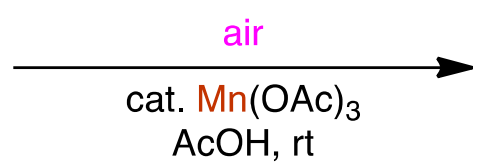

$\mathrm{AcOH}, \mathrm{rt}$<smiles>[R]N1CC(=O)C([R20])(O)C1=O</smiles>

4a-p
a : $\mathrm{R}^{1}=\mathrm{Bn}, \mathrm{R}^{2}=\mathrm{Me}$
i $: \mathrm{R}^{1}=t-\mathrm{Bu}, \mathrm{R}^{2}=\mathrm{Me}$
b : $R^{1}=B n, R^{2}=E t$
j : $\mathrm{R}^{1}=t-\mathrm{Bu}, \mathrm{R}^{2}=\mathrm{Et}$
c : $R^{1}=B n, R^{2}=P r$
$\mathrm{k}: \mathrm{R}^{1}=t-\mathrm{Bu}, \mathrm{R}^{2}=\mathrm{Pr}$
d: $R^{1}=B n, R^{2}=B u$
I $: \mathrm{R}^{1}=t-\mathrm{Bu}, \mathrm{R}^{2}=\mathrm{Bu}$
e : $R^{1}=\mathrm{Bn}, \mathrm{R}^{2}=\mathrm{C}_{6} \mathrm{H}_{13}$
$\mathrm{m}: \mathrm{R}^{1}=t-\mathrm{Bu}, \mathrm{R}^{2}=\mathrm{C}_{6} \mathrm{H}_{13}$
$f: R^{1}=B u, R^{2}=M e$
$\mathbf{n}: \mathrm{R}^{1}=i-\mathrm{Pr}, \mathrm{R}^{2}=\mathrm{Me}$
g: $R^{1}=B u, R^{2}=E t$
o: $\mathrm{R}^{1}=i-\operatorname{Pr}, \mathrm{R}^{2}=\mathrm{Et}$
$h: R^{1}=B u, R^{2}=B u$
p : $\mathrm{R}^{1}=i-\operatorname{Pr}, \mathrm{R}^{2}=\operatorname{Pr}$

In order to optimize the hydroperoxidation, the reaction was conducted under various reaction conditions, and we finally obtained the hydroperoxide $\mathbf{4 a}$ in $94 \%$ yield under the conditions of room temperature reaction in air for $2 \mathrm{~h}$ using a catalytic amount of $\mathrm{Mn}(\mathrm{OAc})_{3}$ (entry 3). To expand the scope of the reaction, the reaction of other 2,4-pyrrolidinediones $\mathbf{3 b} \mathbf{b}-\mathbf{p}$ was conducted under the 
optimized reaction conditions and similar hydroperoxides $\mathbf{4 b}-\mathbf{p}$ were obtained in excellent yields (entries 4-18). However, the reactions using 1-ethyl-3-methylpyrrolidine-2,4-dione (3q) and ethyl 1-benzylpyrrolidine-2,4-dione-3-carboxylate (3r) gave intractable mixtures and the corresponding hydroperoxides were not isolated. In addition, the reaction of 1-benzyl-3-phenylpyrrolidine-2,4-dione (3s) failed because of the solubility problem. Although the 4-hydroperoxypyrazolidinediones $\mathbf{2 a - h}$ were stable at ambient temperature in air, the 3-hydroperoxypyrrolidinediones $\mathbf{4 a - p}$ gradually decomposed within 2 or 3 days and even when stored in a refrigerator at $-20{ }^{\circ} \mathrm{C}$ for a half year.

Table 2. Aerobic oxidation of 1,3-dialkyl-substituted pyrrolidinediones $\mathbf{3 a}-\mathbf{p}^{\text {a }}$.

\begin{tabular}{ccccc}
\hline Entry & $\mathbf{3}$ & $\mathbf{3 : M n}(\mathbf{O A c})_{\mathbf{3}} \mathbf{b}$ & Time/h & Product/yield (\%) $\mathbf{c}^{\mathbf{b}}$ \\
\hline 1 & $\mathbf{3 a}$ & $1: 1$ & 2 & $\mathbf{4 a}(65)$ \\
2 & $\mathbf{3 a}$ & $1: 0.1$ & 14 & $\mathbf{4 a}(68)$ \\
3 & $\mathbf{3 a}$ & $1: 0.1$ & 2 & $\mathbf{4 a}(94)$ \\
4 & $\mathbf{3 b}$ & $1: 0.1$ & 2 & $\mathbf{4 b}(95)$ \\
5 & $\mathbf{3 c}$ & $1: 0.1$ & 2 & $\mathbf{4 c}(98)$ \\
6 & $\mathbf{3 d}$ & $1: 0.1$ & 2 & $\mathbf{4 d}(93)$ \\
7 & $\mathbf{3 e}$ & $1: 0.1$ & 2 & $\mathbf{4 e}(96)$ \\
8 & $\mathbf{3 f}$ & $1: 0.1$ & 1.5 & $\mathbf{4 f}(91)$ \\
9 & $\mathbf{3 g}$ & $1: 0.1$ & 1.5 & $\mathbf{4 g}(90)$ \\
10 & $\mathbf{3 h}$ & $1: 0.1$ & 1.5 & $\mathbf{4 h}(95)$ \\
11 & $\mathbf{3 i}$ & $1: 0.1$ & 1.5 & $\mathbf{4 i}(90)$ \\
12 & $\mathbf{3 j}$ & $1: 0.1$ & 1.5 & $\mathbf{4 j}(96)$ \\
13 & $\mathbf{3 k}$ & $1: 0.1$ & 1.5 & $\mathbf{4 k}(99)$ \\
14 & $\mathbf{3 l}$ & $1: 0.1$ & 1.5 & $\mathbf{4 l}(99)$ \\
15 & $\mathbf{3 m}$ & $1: 0.1$ & 1.5 & $\mathbf{4 m}(98)$ \\
16 & $\mathbf{3 n}$ & $1: 0.1$ & 1.5 & $\mathbf{4 n}(95)$ \\
17 & $\mathbf{3 0}$ & $1: 0.1$ & 1.5 & $\mathbf{4 0}(97)$ \\
18 & $\mathbf{3 p}$ & $1: 0.1$ & 1.5 & $\mathbf{4 p}(98)$ \\
\hline
\end{tabular}

${ }^{\text {a }}$ The reaction of $3(1 \mathrm{mmol})$ was carried out in $\mathrm{AcOH}(25 \mathrm{~mL})$ at ambient temperature in air;

${ }^{\mathrm{b}}$ Molar ratio; ${ }^{\mathrm{c}}$ The yield is based on the amount of $\mathbf{3}$ used.

\subsection{Aerobic Oxidation of 3-Alkyl-1,5-dimethylbarbituric Acids 5a-e and 3-Butyl-4-hydroxy-2- quinolinone (7)}

We next investigated the reaction of other biologically important heterocyclic 1,3-dicarbonyl compounds, such as 5-monosubstituted barbituric acids 5a-e and 3-butyl-4-hydroxy-2-quinolinone 7. The barbituric acids 5a-e were prepared by Pd-catalyzed reductive alkylation of 1,3-dimethylbarbituric acid with acetone and aldehydes [49]. The quinolinone 7 was prepared by condensation of aniline and diethyl butylmalonate followed by dehydration (see Experimental section) [50-52]. With the barbituric acids 5a-e and the quinolinone 7 in hand, the aerobic oxidation was carried out under similar reaction conditions, and very similar results were obtained, giving the corresponding hydroperoxides $\mathbf{6 a - e}$ and $\mathbf{8}$, respectively, in excellent to good yields (Scheme 4 and Table 3). 
Scheme 4. Aerobic oxidation of barbituric acids 5a-e and 4-hydroxy-2-quinolinone 7.

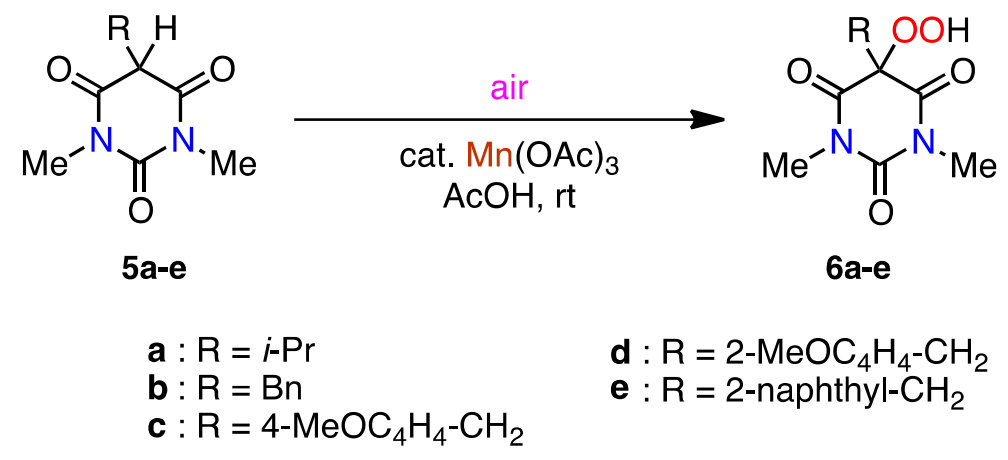<smiles>O=c1[nH]c2ccccc2c(O)c1Br</smiles>

7

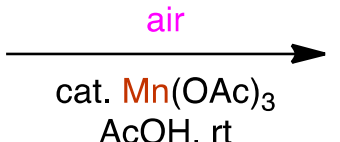

$\mathrm{AcOH}, \mathrm{rt}$<smiles>O=C1Nc2ccccc2C(=O)C1(O)Br</smiles>

8

Table 3. Aerobic oxidation of barbituric acids 5a-e and 4-hydroxy-2-quinolinone $7^{\mathrm{a}}$.

\begin{tabular}{ccccc}
\hline Entry & Amide & Amide:Mn(OAc) $\mathbf{3}^{\mathbf{b}}$ & Time/h & Product $/ \mathbf{y i e l d}(\%)^{\mathbf{c}}$ \\
\hline 1 & $\mathbf{5 a}$ & $1: 0.1$ & 4 & $\mathbf{6 a}(80)$ \\
2 & $\mathbf{5 b}$ & $1: 0.1$ & 2 & $\mathbf{6 b}(90)$ \\
3 & $\mathbf{5 c}$ & $1: 0.1$ & 4 & $\mathbf{6 c}(94)$ \\
4 & $\mathbf{5 d}$ & $1: 0.1$ & 4 & $\mathbf{6 d}(94)$ \\
5 & $\mathbf{5 e}$ & $1: 0.1$ & 2 & $\mathbf{6 e}(88)$ \\
6 & $\mathbf{7}$ & $1: 0.1$ & 2 & $\mathbf{8}(57)$ \\
\hline
\end{tabular}

${ }^{\text {a }}$ The reaction of $5(1 \mathrm{mmol})$ was carried out in $\mathrm{AcOH}(30 \mathrm{~mL})$ at ambient temperature in air;

${ }^{\mathrm{b}}$ Molar ratio; ${ }^{\mathrm{c}}$ The yield is based on the amount of $\mathbf{5}$ or $\mathbf{7}$ used.

\subsection{Mechanism for the Formation of Hydroperoxides $\mathbf{2}, \mathbf{4}, \mathbf{6}$, and $\mathbf{8}$}

The aerobic oxidation might be explained by a radical chain mechanism. To rationalize our experimental results, we presume the formation of $\mathrm{Mn}(\mathrm{III})$-enolate complex A in situ undergoing single-electron transfer (SET) to give 1,3-dicarbonyl radical B and the reduced Mn(II) (Scheme 5) [31-36]. This is the initiation step of the radical chain reaction. The 1,3-dicarbonyl radical $\mathbf{B}$ could be trapped by dissolved molecular oxygen in solution to produce the peroxy radical $\mathbf{C}[53,54]$. The radical $\mathbf{C}$ could simply abstract a hydrogen atom from the cyclic amides to give the product hydroperoxides and another molecule of 1,3-dicarbonyl radical $\mathbf{B}$, which continues the radical chain reaction. Since the redox potential $\left(E^{\circ}\right)$ of $\mathrm{Mn}(\mathrm{III}) / \mathrm{Mn}$ (II) is $1.54 \mathrm{~V}$, it seems that the $\mathrm{Mn}(\mathrm{III})$ acts as an initiator rather than as a catalyst such as $\mathrm{Cu}(\mathrm{II}) / \mathrm{Cu}(\mathrm{I})\left(E^{\circ}=0.123 \mathrm{~V}\right)$ [55-67]. 
Scheme 5. Mn(III)-initiated autoxidation of cyclic amides.

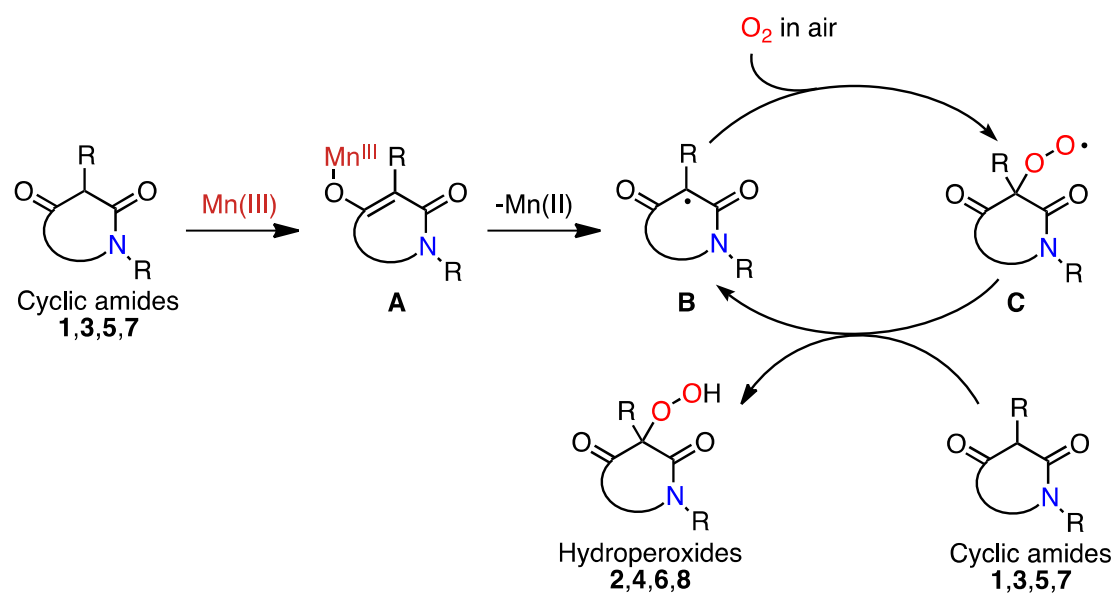

Involvement of the peroxy radical as well as the hydroperoxide intermediate in the course of transition metal-catalyzed autoxidation with different 1,3-dicarbonyl compounds has been proposed earlier [58,59]; however, there is only one report on the detection and identification of such a peroxy radical by electron spin resonance (ESR) [60]. To the best of our knowledge, there are no reports on the isolation and characterization of 2-hydroperoxy-1,3-dicarbonyl compounds in the transition metal-mediated autoxidation of the 1,3-dicarbonyl compounds, except for Hasegawa's work [61]. They showed that introduction of the hydroperoxy functionality at the active methylene position of 1,3-dicarbonyl compounds could be accomplished by dye-sensitized photoreaction of singlet oxygen with the enolic 1,3-dicarbonyl compounds [61]. Although CAN also mediated the hydroperoxidation (Table 1, entry 6), the role of CAN could be accounted for by a similar function of Mn(III) during the reaction [62-64].

\subsection{Conversion of the Hydroperoxides $\mathbf{2}$ and $\mathbf{6}$ into the Alcohols $\mathbf{9}$ and $\mathbf{1 0}$}

When the aerobic oxidation of the pyrazolidinedione 1d was carried out for a longer reaction period with a catalytic amount of $\mathrm{Mn}(\mathrm{OAc})_{3}$ in $\mathrm{AcOH}$ or for shorter reaction time in EtOH, a substantial amount of hydroxylated product 9d was produced along with the hydroperoxide 2d (Scheme 6 and Table 4, entries 2-4). Furthermore, utilizing a stoichiometric amount of CAN as a stronger oxidant than $\mathrm{Mn}(\mathrm{OAc})_{3}$ also gave a similar result (entry 5). The formation of the alcohol 9d might be attributed to the degradation of the corresponding hydroperoxide 2d. As we have mentioned earlier, metal ion-mediated conversion of the 1,3-dicarbonyl compounds into their corresponding 2-hydroxylated derivatives has been well studied [21-30], nevertheless the mechanism associated with this conversion was not well explored and remained more or less ambiguous. In order to scrutinize the production of $9 \mathbf{d}$, the hydroperoxide $2 \mathbf{d}$ was stirred at $23{ }^{\circ} \mathrm{C}$ in $\mathrm{AcOH}$ without the presence of any metal catalyst and under sunlight for $23 \mathrm{~h}$. As a result, no conversion of $2 \mathbf{d}$ to $9 d$ took place and $100 \%$ recovery of 2d was possible after the removal of the solvent (entry 6). Thus, while many alkylhydroperoxides are known to be sensitive to heat [65,66] and light $[67,68]$, the conversion of 2d into $9 \mathbf{d}$ is not thermal or photochemical. However, in the presence of a catalytic amount of $\mathrm{Mn}(\mathrm{OAc})_{3}$ ( 0.01 equiv.) in the same reaction system, $47 \%$ of the $\mathbf{2 d}$ was converted into its corresponding alcohol 9d (entry 7). Carrying out a similar reaction under darkness did not alter the course of the reaction, 
which implies that the $\mathrm{Mn}(\mathrm{III})$-catalyzed degradation is not light-assisted. We then carried out the reaction of 2d under an argon atmosphere with $\mathrm{Mn}(\mathrm{OAc})_{2}$, and we found that $\mathrm{Mn}(\mathrm{OAc})_{2}$ was also effective in the degradation (entry 8). With cerium(IV), $47 \%$ of the alcohol $9 d$ was formed from $2 \mathbf{d}$ (entry 9). A similar degradation was also observed in the reaction of the hydroperoxides $\mathbf{2 c}$, $\mathbf{2 g}$ (entries 10 and 11), the barbituric acid $\mathbf{5 b}$ and the hydroperoxide $\mathbf{6 b}$ (entries 12-17). Therefore, we could draw the conclusion that the transformation of hydroperoxides $\mathbf{2}$ and $\mathbf{6}$ into their corresponding alcohols $\mathbf{9}$ and 10 was due to a similar redox reactions using copper salt which has been extensively studied [69-71]. If the $\mathrm{Mn}(\mathrm{III})$ and $\mathrm{Ce}(\mathrm{IV})$ would function such as $\mathrm{Cu}(\mathrm{II})$, the mechanism of the degradation might be depicted in Scheme 7.

Scheme 6. Conversion of the hydroperoxides into the corresponding alcohols.
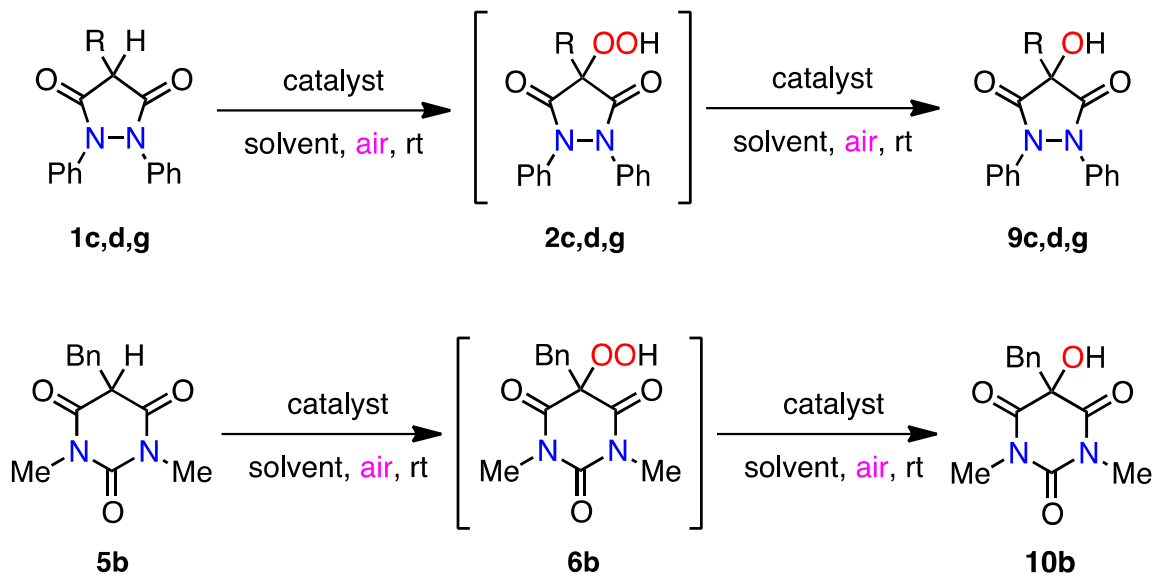

Table 4. Aerobic oxidation of amides under various conditions followed by decomposition a

\begin{tabular}{|c|c|c|c|c|c|c|c|c|}
\hline Entry & Amide & Catalyst & 1:Catalyst ${ }^{\mathrm{b}}$ & Solvent & Time/h & \multicolumn{2}{|c|}{ Product/yield (\%) ${ }^{c}$} & Recovery $/ \%$ \\
\hline 1 & $1 d$ & $\mathrm{Mn}(\mathrm{OAc})_{3}$ & $1: 0.1$ & $\mathrm{AcOH}$ & 2 & 2d (97) & & \\
\hline 2 & 1d & $\mathrm{Mn}(\mathrm{OAc})_{3}$ & 1:0.1 & $\mathrm{AcOH}$ & 12 & 2d (87) & 9d (8) & \\
\hline 3 & 1d & $\mathrm{Mn}(\mathrm{OAc})_{3}$ & $1: 0.2$ & $\mathrm{AcOH}$ & 27 & 2d (52) & 9d (46) & \\
\hline 4 & 1d & $\mathrm{Mn}(\mathrm{OAc})_{3}$ & $1: 0.28$ & $\mathrm{EtOH}$ & 3 & 2d (54) & 9d (41) & \\
\hline 5 & 1d & $\mathrm{CAN}^{\mathrm{d}}$ & $1: 1$ & $\mathrm{MeOH}$ & 1 & 2d (35) & 9d (55) & \\
\hline 6 & 2d & none & & $\mathrm{AcOH}$ & 23 & & & 100 \\
\hline 7 & 2d & $\mathrm{Mn}(\mathrm{OAc})_{3}$ & $1: 0.01$ & $\mathrm{AcOH}$ & 23 & & 9d (47) & 32 \\
\hline $8^{\mathrm{e}}$ & 2d & $\mathrm{Mn}(\mathrm{OAc})_{2}$ & $1: 1$ & $\mathrm{AcOH}$ & 14 & & 9d (25) & 66 \\
\hline 9 & 2d & $\mathrm{CAN}^{\mathrm{d}}$ & $1: 1$ & $\mathrm{MeOH}$ & 2 & & 9d (47) & 33 \\
\hline 10 & $2 c$ & $\mathrm{Mn}(\mathrm{OAc})_{3}$ & $1: 0.01$ & $\mathrm{AcOH}$ & 17 & & $9 \mathrm{c}(45)$ & 48 \\
\hline 11 & $2 \mathrm{~g}$ & $\mathrm{Mn}(\mathrm{OAc})_{3}$ & $1: 0.01$ & $\mathrm{AcOH}$ & 17 & & $\mathbf{9 g}(40)$ & 28 \\
\hline 12 & $5 \mathbf{b}$ & $\mathrm{Mn}(\mathrm{OAc})_{3}$ & $1: 0.1$ & $\mathrm{AcOH}$ & 3 & $\mathbf{6 b}(88)$ & $10 b(7)$ & \\
\hline 13 & $5 b$ & $\mathrm{Mn}(\mathrm{OAc})_{3}$ & 1:0.1 & $\mathrm{AcOH}$ & 5 & $\mathbf{6 b}(79)$ & $10 b(18)$ & \\
\hline 14 & $5 b$ & $\mathrm{CAN}^{\mathrm{d}}$ & $1: 1$ & $\mathrm{MeOH}$ & 0.5 & $\mathbf{6 b}(47)$ & 10b (43) & \\
\hline 15 & $6 b$ & none & & $\mathrm{AcOH}$ & 12 & & & 100 \\
\hline 16 & $6 b$ & $\mathrm{Mn}(\mathrm{OAc})_{3}$ & 1:0.1 & $\mathrm{AcOH}$ & 14 & & 10b (14) & 88 \\
\hline 17 & $6 \mathrm{~b}$ & $\mathrm{Mn}(\mathrm{OAc})_{3}$ & 1:0.4 & $\mathrm{AcOH}$ & 23 & & $10 \mathrm{~b}(40)$ & 50 \\
\hline
\end{tabular}

${ }^{\mathrm{a}}$ The reaction of an amide $(1 \mathrm{mmol})$ was carried out in $\mathrm{AcOH}(30 \mathrm{~mL})$ at room temperature in air;

${ }^{\mathrm{b}}$ Molar ratio; ${ }^{\mathrm{c}}$ Isolated yield is based on the amide used; ${ }^{\mathrm{d}}$ The reaction with ammonium cerium(IV) nitrate (CAN) was carried out at $0{ }^{\circ} \mathrm{C}$; ${ }^{\text {e }}$ The reaction was carried out under an argon atmosphere. 
Scheme 7. Degradation of hydroperoxides by a redox system [69].

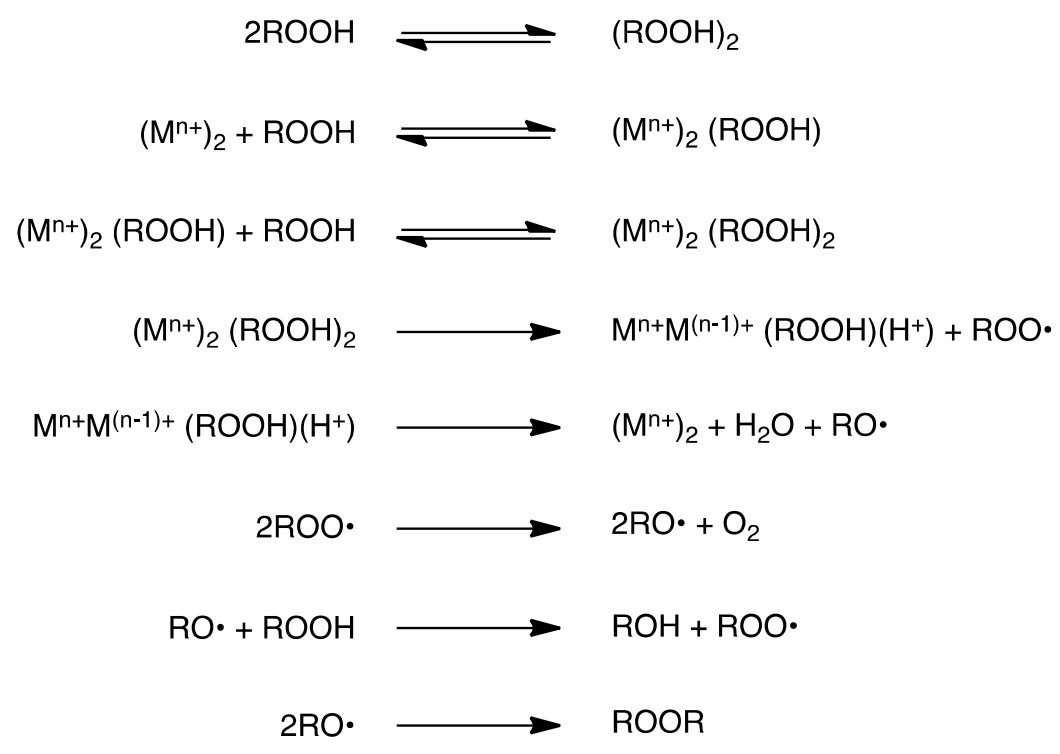

For $M, M n: n=3 ; \mathrm{Ce}: \mathrm{n}=4$

\subsection{Application of the Mn(III)-Mediated Oxygenation}

In order to apply the hydroperoxidation to acyclic $\beta$-oxoamides, cyclic ketones, and esters, the reactions of malonamides 11a,b, cyclopentanonecarboxylate derivatives 13a,b, and substituted dimedones 15 were examined (Scheme 8).

Scheme 8. Aerobic oxidation of malonamides, cyclic $\beta$-diketones and $\beta$-ketoesters.
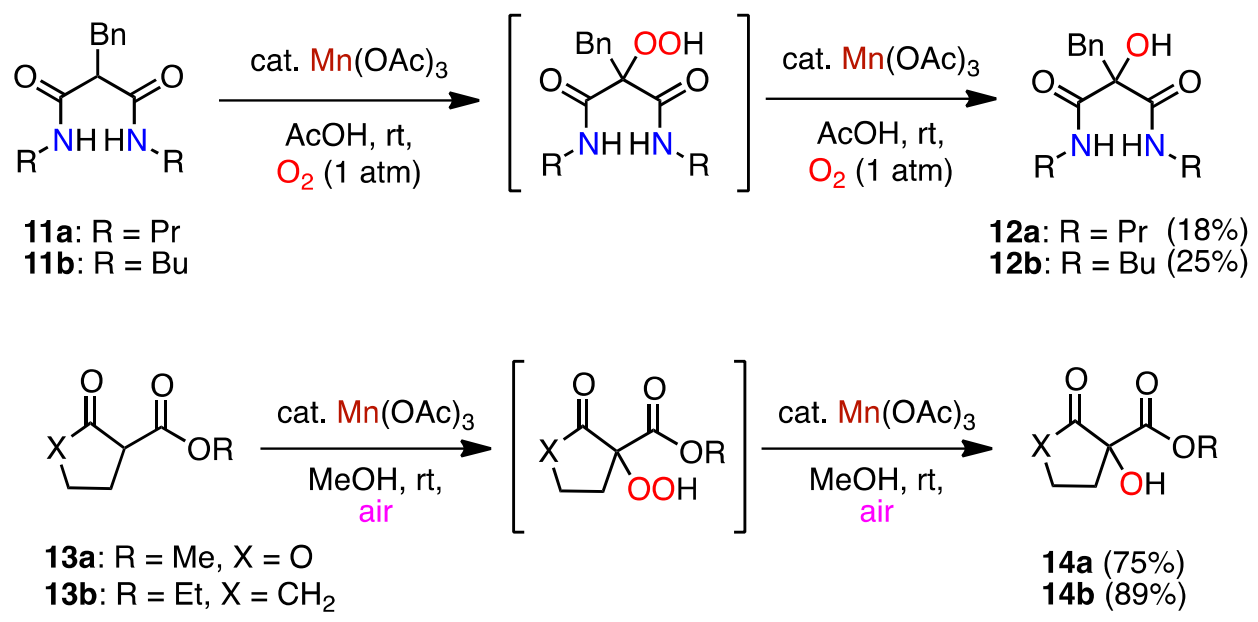<smiles>[R]C1C(=O)CC(C)(C)CC1=O</smiles>

15

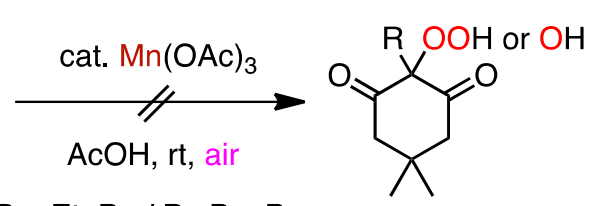

$\mathrm{R}=\mathrm{Et}, \mathrm{Pr}, i-\mathrm{Pr}, \mathrm{Bu}, \mathrm{Bn}$ 
Surprisingly, the malonamides 11a,b were inactive under the aerobic conditions and only afforded the corresponding alcohols 12a and 12b, respectively, under an oxygen atmosphere (1 atm) instead of air. Because the reaction of $\mathbf{1 3 a}, \mathbf{b}$ in $\mathrm{AcOH}$ gave an intractable mixture, the reaction was carried out in $\mathrm{MeOH}$ and the corresponding alcohols 14a,b were isolated (Scheme 8). The dimedone derivatives 15 did not produce any oxygenated products, but 15 were recovered. Therefore, the hydroperoxidation must be characteristic for the cyclic amide derivatives. We also assumed that the corresponding hydroperoxides of $\mathbf{1 1}$ and $\mathbf{1 3}$ were too unstable in the solution containing $\mathrm{Mn}(\mathrm{III})$, and thus readily decomposed to give the corresponding alcohols 12 and 14, respectively, according to the redox system mentioned above (Scheme 7).

The hydroperoxides $\mathbf{2 a}-\mathbf{d}$ and $\mathbf{6 b}$ could be transformed by reduction into their corresponding alcohols 9a-d and 10b, respectively. Simple stirring of equimolar amounts of the hydroperoxide and $\mathrm{Ph}_{3} \mathrm{P}$ in $\mathrm{Et}_{2} \mathrm{O}$ at room temperature gave the corresponding alcohol after a very simple work-up procedure (see Experimental section). The results are summarized in Table 5.

Table 5. Reduction of the hydroperoxides $\mathbf{2 a - d}$ and $\mathbf{6 b}$ using $\mathrm{Ph}_{3} \mathrm{P}^{\mathrm{a}}$.

\begin{tabular}{ccccc}
\hline Entry & ROOH & ROOH:Ph & Pime/h & Product/Yield (\%) $^{\mathbf{b}}$ \\
\hline 1 & 2a & $1: 1$ & 3 & $\mathbf{9 a}(96)$ \\
2 & 2b & $1: 1$ & 3 & $\mathbf{9 b}(97)$ \\
3 & 2c & $1: 1$ & 3 & $\mathbf{9 c}(98)$ \\
4 & 2d & $1: 1$ & 3 & $\mathbf{9 d}(97)$ \\
5 & 6b & $1: 1$ & 3 & $\mathbf{1 0 b}(80)$ \\
\hline
\end{tabular}

${ }^{a}$ The reaction of the hydroperoxides $\mathbf{2 a}-\mathbf{d}$ and $\mathbf{6} \mathbf{b}$ with $\mathrm{Ph}_{3} \mathrm{P}$ was carried out in $\mathrm{Et}_{2} \mathrm{O}$ in air at room temperature; ${ }^{\mathrm{b}}$ Isolated yield is based on $\mathbf{2}$ or $\mathbf{6 b}$ used.

\subsection{Structural Determination of the Hydroperoxides and the Hydroxyl Derivatives}

Characterization of the hydroperoxides and the alcohols deserves comment. All the obtained hydroperoxides in $\mathrm{CH}_{2} \mathrm{Cl}_{2}$ showed a positive potassium iodide-starch test. The structural assignment of the hydroperoxides 2, 4, 6, and 8 was based on their ${ }^{1} \mathrm{H}-\mathrm{NMR},{ }^{13} \mathrm{C}-\mathrm{NMR}$, IR spectra as well as their elemental analyses. For example, the 4-hydroperoxypyrazolidinedione $\mathbf{2 g}$ showed a singlet at $\delta 11.21 \mathrm{ppm}$ in the ${ }^{1} \mathrm{H}-\mathrm{NMR}$ spectrum due to $\mathrm{OOH}$ group. In the ${ }^{13} \mathrm{C}-\mathrm{NMR}$ spectrum, the amide carbonyl carbon appeared at $\delta 167.7 \mathrm{ppm}$ and a quaternary carbon $\mathrm{C}-4$ bearing the $\mathrm{OOH}$ group at $\delta$ $86.7 \mathrm{ppm}$. In addition, the elemental analysis and FAB HRMS supported the molecular formula of $\mathrm{C}_{22} \mathrm{H}_{18} \mathrm{~N}_{2} \mathrm{O}_{4}$. The structure was finally confirmed by X-ray crystallography. A colorless single crystal of $\mathbf{2 g}$ was successfully grown from $\mathrm{CH}_{2} \mathrm{Cl}_{2}$-benzene of approximate dimensions of $0.25 \times 0.50 \times 0.10$ $\mathrm{mm}$ was mounted on a glass fiber. All measurements were made on an imaging plate diffractometer with graphite monochromated Mo-K $\alpha$ radiation. Cell constants and an orientation matrix for data collection corresponded to a primitive triclinic cell with dimensions were obtained as the triclinic space group $P-1$ with cell constants $a=10.3233, b=10.4273, c=12.9985 \AA, V=1283.0 \AA^{3}$, and $\alpha=95.792, \beta=104.504, \gamma=105.643^{\circ}$. The structure was solved by direct methods and expanded using Fourier techniques (see Supplementary data). The ORTEP drawing of $\mathbf{2 g}$ is shown in Figure 1. The intramolecular hydrogen-bonding in $\mathbf{2 g}$ could be visualized between the terminal hydroperoxy 
oxygen and the carbonyl oxygen, $\mathrm{O}(4)-\mathrm{O}(1)(2.705 \AA)[32,33,37-40,42]$. The other hydroperoxides obtained from the aerobic oxidation showed similar spectroscopic features.

Figure 1. ORTEP drawing of 4-benzyl-4-hydroperoxy-1,2-diphenylpyrazolidine-3,5-dione (2g).

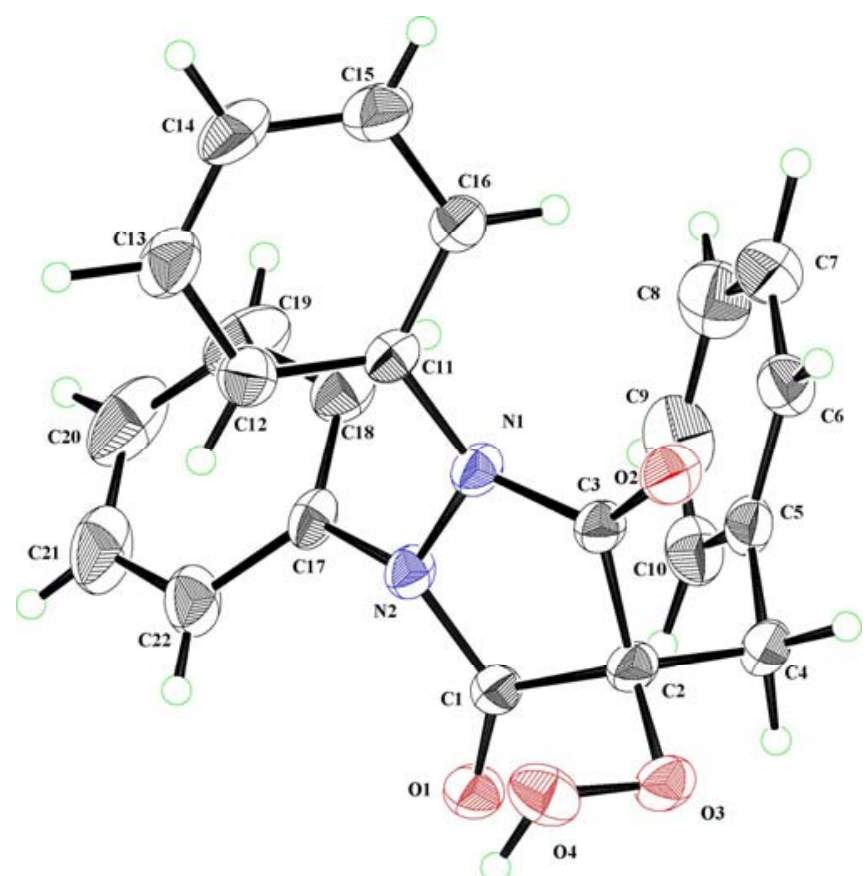

In the case of the alcohol derivatives $9, \mathbf{1 0}, \mathbf{1 2}$, and 14, the characteristic spectral features of the $\mathrm{OH}$ group were observed in the IR and NMR spectra. For example, 9g showed an absorption band at $3298 \mathrm{~cm}^{-1}$ in the IR spectrum corresponding to the $\mathrm{OH}$ group and a singlet at $\delta 4.88 \mathrm{ppm}$ in the ${ }^{1} \mathrm{H}-\mathrm{NMR}$ spectrum due to the $\mathrm{OH}$ group. In the ${ }^{13} \mathrm{C}$-NMR spectrum, the quaternary carbon $\mathrm{C}-4$ bearing the $\mathrm{OH}$ group appeared at $\delta 75.8 \mathrm{ppm}$ and this is significantly different from that having the $\mathrm{OOH}$ group (Table 6) [72]. In addition, the elemental analysis of 9g supported the molecular formula of $\mathrm{C}_{22} \mathrm{H}_{18} \mathrm{~N}_{2} \mathrm{O}_{3}$. Therefore, it is easy to distinguish the corresponding alcohols from the hydroperoxides.

Table 6. ${ }^{13} \mathrm{C}$-NMR chemical shifts of the quaternary carbon bearing the $\mathrm{OOH}$ and $\mathrm{OH}$ group ${ }^{\text {a }}$.

\begin{tabular}{|c|c|c|c|}
\hline Hydroperoxide & ${ }^{13} \mathrm{C}-\mathrm{OOH} / \mathrm{ppm}$ & Alcohol & ${ }^{13} \mathrm{C}-\mathrm{OH} / \mathrm{ppm}$ \\
\hline $2 \mathbf{a}$ & 81.6 & $9 a$ & 71.1 \\
\hline $2 b$ & 85.8 & $9 \mathrm{~b}$ & 74.7 \\
\hline 2c & 85.3 & $9 c$ & 74.0 \\
\hline 2d & 87.6 & 9d & 76.3 \\
\hline
\end{tabular}


Table 6. Cont.

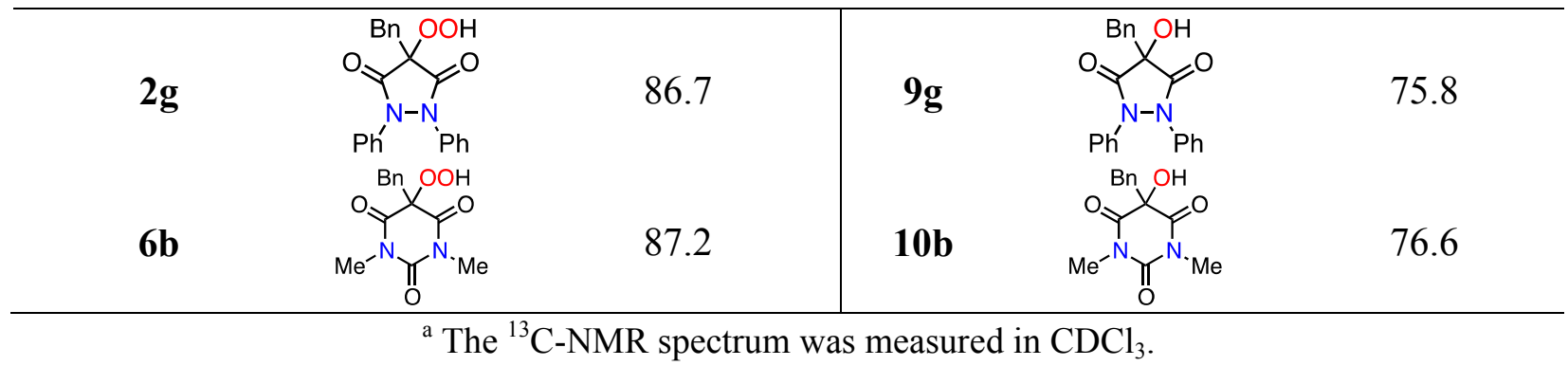

\section{Experimental}

\subsection{Measurements}

Melting points were taken using a Yanagimoto micromelting point apparatus and were not corrected. The NMR spectra were recorded using a JNM AL300 or ECX 500 FT-NMR spectrometer at 300 or $500 \mathrm{MHz}$ for ${ }^{1} \mathrm{H}$ and 75 or $125 \mathrm{MHz}$ for ${ }^{13} \mathrm{C}$, with tetramethylsilane as the internal standard. The chemical shifts are reported in $\delta$ values (ppm) and the coupling constants in Hz. The IR spectra were measured in $\mathrm{CHCl}_{3}$ or $\mathrm{KBr}$ using a Shimadzu 8400 FT IR spectrometer and expressed in $\mathrm{cm}^{-1}$. The EI MS spectra were measured by a Shimadzu QP-5050A gas chromatograph-mass spectrometer with the ionizing voltage of $70 \mathrm{eV}$. The high-resolution mass spectra and the elemental analysis were performed at the Instrumental Analysis Center, Kumamoto University, Kumamoto, Japan.

\subsection{Materials}

Manganese(II) acetate tetrahydrate, $\mathrm{Mn}(\mathrm{OAc})_{2} \bullet 4 \mathrm{H}_{2} \mathrm{O}$, was purchased from Wako Pure Chemical Ind., Ltd. Manganese(III) acetate dihydrate, $\mathrm{Mn}(\mathrm{OAc})_{3} \cdot 2 \mathrm{H}_{2} \mathrm{O}$, was prepared according to the method described in the literature [73,74]. 4-Alkyl-1,2-diphenylpyrazolidine-3,5-diones 1a-h were prepared by the condensation of a suitable alkylmalonate with 1,2-diphenylhydrazine in the presence of $\mathrm{NaH}$ in boiling chlorobenzene [17]. Methyl 2-oxotetrahydrofuran-3-carboxylate (13a) and ethyl 2-oxocyclopentanecarboxylate (13b) were purchased from Tokyo Chemical Industry Co., Ltd., and used as received. The physical data for the pyrazolidinediones $\mathbf{1} \mathbf{a}-\mathbf{h}$ are given in supplementary data.

1,3-Dialkyl-substituted pyrrolidine-2,4-diones 3a-s were prepared as follows [75-81]. To a mixture of ethyl (benzylamino)acetate $(3.22 \mathrm{~mL} ; 17.4 \mathrm{mmol})$ and triethylamine $(4.85 \mathrm{~mL} ; 34.8 \mathrm{mmol})$ in $\mathrm{CHCl}_{3}(25 \mathrm{~mL})$ was dropwise-added propanoyl chloride $(1.65 \mathrm{~mL} ; 19.2 \mathrm{mmol})$ at $0{ }^{\circ} \mathrm{C}$ over $15 \mathrm{~min}$. After stirring for another $1.5 \mathrm{~h}$ at room temperature, the mixture was diluted with $\mathrm{CHCl}_{3}$ to $50 \mathrm{~mL}$ and washed with a $5 \%$ aqueous $\mathrm{AcOH}$ solution $(25 \mathrm{~mL})$, water $(50 \mathrm{~mL})$, brine $(25 \mathrm{~mL})$, dried over anhydrous $\mathrm{MgSO}_{4}$, and then concentrated to dryness, affording the liquid propanoyl-protected (benzylamino)acetate with sufficient purity for use in the next step.

To a refluxing suspension of $\mathrm{NaH}(60 \%$ dispersion in mineral oil) $(500 \mathrm{mg} ; 11.03 \mathrm{mmol})$ and tetrahydrofuran $(50 \mathrm{~mL})$ in a $300 \mathrm{~mL}$ three-necked flask was dropwise-added the prepared propanoylprotected (benzylamino)acetate $(2.5 \mathrm{~g} ; 10.03 \mathrm{mmol})$ in tetrahydrofuran $(50 \mathrm{~mL})$. After this addition, the mixture was continuously heated under reflux for $12 \mathrm{~h}$. A pale yellow solid was formed during the heating and then filtered under suction. The obtained solid was dissolved in a minimum volume of water and very carefully acidified with $2 \mathrm{M} \mathrm{H}_{2} \mathrm{SO}_{4}$, giving 1-benzyl-3-methyl-2,4-pyrrolidinedione 
(keto form of 3a) as a crude precipitate. The precipitate was purified by silica gel column chromatography, eluting with a mixture of EtOAc and hexane followed by recrystallization using the appropriate solvent. The other 2,4-pyrrolidinediones $\mathbf{3 b}$-s were prepared in a manner similar to that described above. The physical data for the pyrrolidinediones 3a-s are given in the Supplementary Data.

5-Alkyl-1,3-dimethylbarbituric acids 5a-e were prepared as follows [49]: 1,3-Dimethylbarbituric acid $(5 \mathrm{mmol})$ and $10 \% \mathrm{Pd}-\mathrm{C}(0.2 \mathrm{~g})$ were added to a mixture of acetone $(20 \mathrm{~mL}), \mathrm{AcOH}(20 \mathrm{~mL})$, and water $(10 \mathrm{~mL})$. A few drops of concentrated $\mathrm{H}_{2} \mathrm{SO}_{4}$ were added and the mixture was heated at $50{ }^{\circ} \mathrm{C}$ under hydrogen $(2 \mathrm{~atm})$ for $4 \mathrm{~h}$ using a glass reactor. The mixture was filtered in a Celite column and the filtrate was extracted with $\mathrm{CHCl}_{3}$. The extract was washed with water several times and a saturated aqueous solution of $\mathrm{NaHCO}_{3}$, and then dried over anhydrous $\mathrm{MgSO}_{4}$. After removal of the solvent, the crude product was recrystallized from $\mathrm{Et}_{2} \mathrm{O}$ /hexane, giving 1,3-dimethyl-5-i-proprylbarbituric acid (5a) in $90 \%$ yield. A similar reaction of the barbituric acid $(5 \mathrm{mmol})$ with 2 -naphthaldehyde $(5 \mathrm{mmol})$ was carried out in $\mathrm{MeOH}(30 \mathrm{~mL})$ at the reflux temperature for $10 \mathrm{~h}$. After the same work-up, 5-(2-naphthyl)methyl-1,3-dimethylbarbituric acid 5e was obtained in $88 \%$ yield. Other benzyl-substituted barbituric acids $\mathbf{5 b}-\mathbf{d}$ were prepared in the same manner. The physical data for the barbituric acids $\mathbf{5 a}-\mathbf{e}$ are given in supplementary data.

3-Butyl-4-hydroxy-2-quinolinone 7 was prepared according to the standard procedure described in the literature [50-52]. Aniline $(2.80 \mathrm{~g} ; 30 \mathrm{mmol})$ and diethylbutyl malonate $(6.51 \mathrm{~g} ; 30 \mathrm{mmol})$ were heated at $150{ }^{\circ} \mathrm{C}$ for $20 \mathrm{~h}$. Water $(30 \mathrm{~mL})$ was added and the mixture was extracted with $\mathrm{CH}_{2} \mathrm{Cl}_{2}$. The extract was washed with $2 \mathrm{M} \mathrm{HCl}$, water and dried over anhydrous $\mathrm{Na}_{2} \mathrm{SO}_{4}$. After removal of the solvent, ethyl 2-(phenylcarbamoyl)hexanoate $(28 \mathrm{mmol})$ was obtained. The hexanoate in EtOH $(10 \mathrm{~mL})$ was hydrolyzed with $6 \mathrm{M} \mathrm{NaOH}(20 \mathrm{~mL})$ in $\mathrm{EtOH}(20 \mathrm{~mL})$ at room temperature for $1 \mathrm{~h}$. After acidifying the solution with $2 \mathrm{M} \mathrm{HCl}$, the precipitates were filtered with suction. The obtained solid acid was dehydrated in PPA, which was poured into water and then neutralized using $6 \mathrm{M} \mathrm{NaOH}$ to $\mathrm{pH} 4$, giving 7 as a precipitate $(3.67 \mathrm{~g} ; 56 \%$ ). The physical data for the quinolinone 7 are given in the Supplementary Data.

2-Benzyl- $N^{1}, N^{3}$-dipropylmalonamide (11a) and 2-benzyl- $N^{1}, N^{3}$-dibutylmalonamide (11b) were prepared by the reaction of diethyl 2-benzylmalonamide $(2.50 \mathrm{~g})$ with propylamine and butylamine $(50 \mathrm{~mL})$, respectively, at reflux temperature for $24 \mathrm{~h}$ followed by removal of the amine unchanged under reduced pressure to give a colorless solid which was recrystallized with $\mathrm{CHCl}_{3} /$ hexane [82]. The physical data for the malonamides $\mathbf{1 1 a}$ and $\mathbf{1 1 b}$ are given in the Supplementary Data.

\subsection{Mn(III)-Initiated Aerobic Oxidation of Heterocyclic 1,3-Dicarbonyl Compounds 1a-h, 3a-p, 5a-e, and 7}

A typical procedure is as follows: to a solution of the cyclic amide $(1 \mathrm{mmol})$ in glacial $\mathrm{AcOH}(25 \mathrm{~mL})$, $\mathrm{Mn}(\mathrm{OAc})_{3} \cdot 2 \mathrm{H}_{2} \mathrm{O}(26.8 \mathrm{mg} ; 0.1 \mathrm{mmol})$ was added. The mixture was stirred at room temperature in air for $1.5-2 \mathrm{~h}$, and then the reaction was quenched by adding water $(25 \mathrm{~mL})$ to the mixture. The aqueous reaction mixture was extracted three times with $\mathrm{CH}_{2} \mathrm{Cl}_{2}(30 \mathrm{~mL})$ and the combined extract was washed with water, then a saturated aqueous solution of $\mathrm{NaHCO}_{3}$, dried over anhydrous $\mathrm{MgSO}_{4}$, and concentrated to dryness. Although the product was almost pure, it was further purified by silica gel flash column 
chromatography, eluting with $\mathrm{Et}_{2} \mathrm{O} /$ hexane $(7: 3 \mathrm{v} / \mathrm{v})$ or EtOAc/hexane $(8: 2 \mathrm{v} / \mathrm{v})$ if needed. The physical data for the hydroperoxides $\mathbf{2} \mathbf{a}-\mathbf{h}, \mathbf{4 a}-\mathbf{p}, \mathbf{6 a}-\mathbf{e}$, and $\mathbf{8}$ are given in the Supplementary Data.

\subsection{Conversion of the Hydroperoxides $\mathbf{2}$ and $\mathbf{6}$ into the Alcohols $\mathbf{9}$ and $\mathbf{1 0}$}

The redox reaction of the hydroperoxide $\mathbf{2 c}, \mathbf{2 d}, \mathbf{2 g}, \mathbf{6 b}(1 \mathrm{mmol})$ was carried out in $\mathrm{AcOH}(30 \mathrm{~mL})$ at room temperature in air. The molar ratio of the catalyst and the reaction times are described in Table 4. After the usual work-up, the corresponding alcohols $9 \mathrm{c}, 9 \mathrm{~d}, 9 \mathrm{~g}$, and $\mathbf{1 0 b}$ were obtained. On the other hand, the reduction of the hydroperoxides $\mathbf{2 a -}-\mathbf{d}$ and $\mathbf{6} \mathbf{b}$ using $\mathrm{Ph}_{3} \mathrm{P}$ is as follows: to the hydroperoxide $(0.5 \mathrm{mmol})$ in $\mathrm{Et}_{2} \mathrm{O}(10 \mathrm{~mL})$, a solution of $\mathrm{Ph}_{3} \mathrm{P}(0.5 \mathrm{mmol})$ in $\mathrm{Et}_{2} \mathrm{O}(10 \mathrm{~mL})$ was dropwise added and stirred for $3 \mathrm{~h}$ at room temperature. Water $(20 \mathrm{~mL})$ was added to the reaction mixture and then extracted with $\mathrm{CH}_{2} \mathrm{Cl}_{2}$. The extract was dried over anhydrous $\mathrm{Na}_{2} \mathrm{SO}_{4}$ and then evaporated to dryness. Simple recrystallization from $\mathrm{Et}_{2} \mathrm{O} /$ hexane gave the pure crystalline alcohol. The physical data for the alcohols $\mathbf{9 a}-\mathbf{d}, \mathbf{9 g}$, and $\mathbf{1 0 b}$ are given in the Supplementary Data.

\subsection{Aerobic Oxidation of $\mathbf{1 d}, \mathbf{2 d}$, and $\mathbf{5 b}$ Using Ammonium Cerium (IV) Nitrate (CAN)}

A typical procedure is as follows: to an ice-cooled solution of the substrate $\mathbf{1 d}, \mathbf{2 d}$, or $\mathbf{5 b}$ (1 mmol) in $\mathrm{MeOH}(20 \mathrm{~mL})$, a solution of ammonium cerium(IV) nitrate (CAN) (1 mmol) in $\mathrm{MeOH}(10 \mathrm{~mL})$ was dropwise-added and stirred in air until the orange color of Ce(IV) disappeared. The reaction was quenched by adding water $(25 \mathrm{~mL})$. The aqueous reaction mixture was extracted three times with $\mathrm{CH}_{2} \mathrm{Cl}_{2}(30 \mathrm{~mL})$, and the combined extract was washed with water, saturated brine, dried over anhydrous $\mathrm{Na}_{2} \mathrm{SO}_{4}$, and then concentrated to dryness. The residue was separated by a silica gel column, eluted with EtOAc/hexane (7:3 v/v). The obtained products $\mathbf{2 d}, \mathbf{9 d}, \mathbf{6 b}$, and 10b were further purified by recrystallization from the solvent described above.

\subsection{Mn(III)-Initiated Aerobic Oxidation of Acyclic Amides 11a,b, ketones 13b, and Esters $\mathbf{1 3 b}, \mathbf{1 5}$}

The oxidation of 11a and $11 \mathbf{b}(0.7 \mathrm{mmol})$ was carried out at room temperature in glacial $\mathrm{AcOH}$ $(10 \mathrm{~mL})$ in the presence of $\mathrm{Mn}(\mathrm{OAc})_{3} \cdot 2 \mathrm{H}_{2} \mathrm{O}(0.42 \mathrm{mmol})$ under an oxygen atmosphere $(1 \mathrm{~atm})$ for $29 \mathrm{~h}$. After the usual work-up, the corresponding alcohols 12a and 12b were obtained in poor yields. The physical data for the alcohols $\mathbf{1 2 a}$ and $\mathbf{1 2 b}$ are given in the Supplementary Data.

The aerobic oxidation of cyclopentanonecarboxylate derivatives 13a and 13b was as follows. To a solution of the cyclopentanonecarboxylate $(1 \mathrm{mmol})$ in $\mathrm{MeOH}(10 \mathrm{~mL})$, a mixture of $\mathrm{Mn}(\mathrm{OAc})_{3} \cdot 2 \mathrm{H}_{2} \mathrm{O}$ $(0.1 \mathrm{mmol})$ in $\mathrm{MeOH}(20 \mathrm{~mL})$ was dropwise-added, and the mixture was stirred at room temperature for $12 \mathrm{~h}$ in air. The reaction mixture was then filtered through the silica gel column (eluted with $\mathrm{Et}_{2} \mathrm{O}$ ) to remove the catalyst. After removal of all volatile components using an evaporator, the corresponding alcohols 14a and 14b were obtained as oil. The physical data for the alcohols $14 \mathbf{a}$ and $\mathbf{1 4 b}$ are given in the Supplementary Data.

2-Alkyl-5,5-dimethylcyclohexane-1,3-diones $15(\mathrm{R}=\mathrm{Et}, \mathrm{Pr}, i$-Pr, $\mathrm{Bu}, \mathrm{Bn})$ were prepared by the reaction of dimedone with the corresponding alkylbromide in the presence of sodium ethoxide in boiling ethanol [83]. The Mn(III)-catalyzed aerobic oxidation of 15 was carried out under various conditions; however, no reaction occurred. 


\section{Conclusions}

The facile $\alpha$-oxygenation of cyclic amides was achieved by $\mathrm{Mn}$ (III)-initiated aerobic oxidation under very mild conditions. The direct hydroperoxidation was characteristic for the cyclic amides, such as 4-alkyl-1,2-diphenylpyrazolidine-3,5-diones 1a-h, 3-alkylpyrrolidine-2,4-diones 3a-p, 3-alkyl-1,5-dimethylbarbituric acids 5a-e, and 3-butyl-4-hydroxy-2-quinolinone 7. It was found that the obtained hydroperoxides gradually underwent redox degradation in the presence of $\mathrm{Mn}(\mathrm{III}) / \mathrm{Mn}$ (II) or $\mathrm{Ce}(\mathrm{IV}) / \mathrm{Ce}$ (III) under the conditions to convert into the corresponding alcohols. Acyclic amides and esters, such as malonamides 11a,b and cyclopentanonecarboxylates 13a,b, afforded the alcohols 12a,b and 14a,b, probably derived from a similar redox degradation of the corresponding hydroperoxides. Cyclic diketones, such as dimedone 15, was inactive under the aerobic oxidation conditions. The reason why the hydroperoxides were isolated in this reaction is assumed to be that, (1) it is difficult for the nucleophilic attack of the hydroperoxy group to occur at the amide carbonyl because the electrophilicity of the amide carbonyl carbon should be weak, and (2) the hydroperoxy group is stabilized by intramolecular hydrogen-bonding with the carbonyl group. The hydroperoxides are easily transformed into the corresponding alcohols by normal reduction using $\mathrm{Ph}_{3} \mathrm{P}$.

Antimalarial testing of the hydroperoxide $\mathbf{2 g}$ was also performed using Plasmodium falciparum FCR-3 strain (ATCC 30932), and a weak antimalarial activity (14\% inhibition) was confirmed. In addition, in order to examine an inhibitory effect toward mRNAs in cells, HeLa cells were treated with the hydroperoxide $\mathbf{2 g}$ or $\mathbf{6 b}$. However, an appreciable effect on the intracellular distribution of mRNAs was not observed (data not shown).

\section{Supplementary Materials}

Supplementary materials can be accessed on: http://www.mdpi.com/1420-3049/16/11/9562/s1.

\section{Acknowledgements}

This research was supported by Grants-in-Aid for Scientific Research (C), No. 15550039, No. 19550046, and No. 22550041, from the Japan s of Science. We gratefully acknowledge Teruo Shinmyouzu, Institute for Materials Chemistry and Engineering, Kyushu University, Japan, and Mikio Yasutake, Graduate School of Science and Engineering, Saitama University, Japan, for the measurement of the high resolution FAB mass spectrum and X-ray analysis, and also thank to Yusuke Wataya, Laboratory of Drug Informatics, Faculty of Pharmaceutical Science, Okayama University, Japan, for the antimalarial testing. We deeply appreciate Tokio Tani and Miss Yuko Azuma, Department of Biological Science, Graduate School of Science and Technology, Kumamoto University, Japan, for the mRNAs inhibitory testing.

\section{References and Notes}

1. Chen, B.-C.; Zhou, P.; Davis, F.A.; Ciganek, E. $\alpha$-Hydroxylation of enolates and silyl enol ethers. Org. React. 2003, 62, 1-356. 
2. Vedej, E.; Engler, D.A.; Telschow, J.E. Transition-metal peroxide reactions. Synthesis of $\alpha$-hydroxycarbonyl compounds from enolates. J. Org. Chem. 1978, 43, 188-196 and references cited therein.

3. Abu-Omar, M.M.; Espenson, J.H. Oxidations of cyclic $\beta$-diketones catalyzed by methylrhenium trioxide. Organometallics 1996, 15, 3543-3549.

4. Heathcock, C.H.; Mahain, C.; Schlecht, M.F.; Utawanit, T. A synthetic approach to the quassinoids. J. Org. Chem. 1984, 49, 3264-3274.

5. Davis, F.A.; Clark, C.; Kumar, A.; Chen, B.-C. Asymmetric synthesis of the AB ring segments of daunomycin and 4-demethoxydaunomycin. J. Org. Chem. 1994, 59, 1184-1190.

6. Davis, F.A.; Liu, H.; Chen, B.-C.; Zhou, P. Oxidation of 1,3-dicarbonyl compounds using (camphorylsulfonyl)oxaziridines. Tetrahedron 1998, 54, 10481-10492.

7. Zhang, W.; Watanabe, K.; Cai, X.; Jung, M.E.; Tang, Y.; Zhan, J. Identifying the minimal enzymes required for anhydrotetracycline biosynthesis. J. Am. Chem. Soc. 2008, 130, 6068-6069.

8. Giovanelli, E.; Leroux, S.; Moisan, L.; Carreyre, H.; Thuéry, P.; Buisson, D.-A.; Meddour, A.; Coustard, J.-M.; Thibaudeau, S.; Rousseau, B.; et al. On the elucidation of the mechanism of Vinca alkaloid fluorination in superacidic medium. Org. Lett. 2011, 13, 4116-4119.

9. Büchi, G.; Matsumoto, K.E; Nishimura, H. Total synthesis of ( \pm )-vindorosine. J. Am. Chem. Soc. 1971, 93, 3299-3301.

10. Andriamialisoa, R.Z.; Langlois, N.; Langlois, Y. A new efficient total synthesis of vindorosine and vindoline. J. Org. Chem. 1985, 50, 961-967.

11. Sasaki, Y.; Kato, D.; Boger, D.L. Asymmetric total synthesis of vindorosine, vindoline, and key vinblastine analogues. J. Am. Chem. Soc. 2010, 132, 13533-13544.

12. Rannoux, C.; Roussi, F.; Martin, M.-T.; Guéritte, F. Elaboration of vinblastine hybrids using a reactive in situ generated $N$-carboxyanhydride. Org. Biomol. Chem. 2011, 9, 4873-4881.

13. Zhu, J.; Klunder, J.H.; Zwanenburg, B. Stereospecific total synthesis of (-)-kjellmanianone and a revision of its absolute configuration. Tetrahedron Lett. 1994, 35, 2787-2790.

14. Charest, M.G.; Lerner, C.D.; Brubaker, J.D.; Siegel, D.R.; Myers. A.G. A convergent enantioselective route to structurally diverse 6-deoxytetracycline antibiotics. Science 2005, 308, 395-398.

15. Mark, G.; Charest, M.G.; Siegel, D.R.; Myers, A.G. Synthesis of (-)-tetracycline. J. Am. Chem. Soc. 2005, 127, 8292-8293.

16. Reed, G.A.; Griffin, I.O.; Eling, T.E. Inactivation of prostaglandin H synthase and prostacyclin synthase by phenylbutazone. Requirement for peroxidative metabolism. Mol. Pharmacol. 1985, 27, 109-114.

17. Vennerstorm, J.L.; Holmes, T.J., Jr. Preparation and evaluation of electrophilic derivatives of phenylbutazone as inhibitors of prostaglandin- $H$-synthase. $J$. Med. Chem. 1987, 30, 563-567.

18. Mentz, V.P.; Schulz, M.; Kluge, R. Chemische darstellung von phenylbutazon-hydroperoxid und prüfung der substanz auf herzwirksamkeit unter in-vitro- und in-vivo-bedingungen. Arzneim.Frosch. 1987, 37, 1229-1232.

19. Rechenberg, H.K.V. Phenylbutazone, 2nd ed.; Edward Arnold Ltd.: London, UK, 1962. 
20. Chauhan, S.M.S.; Srinivas, K.A.; Mohapatra, P.P. Oxidation of phenylbutazone with hydrogen peroxide catalyzed by 5,10,15,20-tetraarylporphyrinoiron(III) chlorides in dichloromethane. Ind. J. Chem. 1999, 31B, 724-725 and references cited therein.

21. Demir, A.S.; Jeganathan, A. Selective oxidation of $\alpha, \beta$-unsaturated ketones at the $\alpha^{\prime}$-position. Synthesis 1992, 235-247.

22. Vedejs, E.; Engler, D.A.; Telschow, J.E. Transition-metal peroxide reactions. Synthesis of $\alpha$-hydroxycarbonyl compounds from enolates. J. Org. Chem. 1978, 43, 188-196.

23. Hubert, A.J.; Starcher, P.S. The Baeyer-Villiger oxidation of alkyl oxocyclohexanecarboxylates. J. Chem. Soc. C 1968, 2500-2502.

24. Adam, W.; Smerz, A.K. Nickel-catalyzed hydroxylation of 1,3-dicarbonyl compounds by dimethyldioxirane. Tetrahedron 1996, 52, 5799-5804.

25. Christoffers, J. Novel manganese-catalyzed $\alpha$-oxidation of cyclic $\beta$-keto esters with molecular oxygen. J. Org. Chem. 1999, 64, 7668-7669.

26. Christoffers, J.; Wenner, T. Cerium-catalyzed $\alpha$-oxidation of $\beta$-dicarbonyl compounds with molecular oxygen. SynLett 2002, 119-121.

27. Christoffers, J.; Werner, T.; Unger, S.; Frey, W. Preparation of acyloins by cerium-catalyzed, direct hydroxylation of $\beta$-dicarbonyl compounds with molecular oxygen. Eur. J. Org. Chem. 2003, 425-431.

28. Baucherel, X.; Levoirier, E.; Uziel, J.; Juge, S. Monohydroxylation of cyclic and acyclic $\beta$-keto esters with molecular oxygen catalyzed by cobalt(II) chloride in neutral conditions. Tetrahedron Lett. 2000, 41, 1385-1387.

29. Nair, V.; Nair, L.G.; Mathew, J. Cerium(IV) mediated oxygenation of dialkyl malonates: A novel synthesis of tartronic acid derivatives. Tetrahedron Lett. 1998, 39, 2801-2804.

30. Watanabe, T.; Ishikawa, T. Mild air-oxidation of 1,3-dicarbonyl compounds with cesium salts: Novel $\alpha$-hydroxylation accompanied by partial hydrolysis of malonate derivatives. Tetrahedron Lett. 1999, 40, 7795-7798.

31. Nishino, H. The facile synthesis of dihydrofurans by the oxidation of olefins with tris(2,4pentanedionato)manganese(III). Bull. Chem. Soc. Jpn. 1985, 58, 1922-1927.

32. Tategami, S.; Yamada, T.; Nishino, H.; Korp, J.D.; Kurosawa, K. Formation of 1,2dioxacyclohexanes by the reaction of alkenes with tris(2,4-pentanedionato)manganese(III) or with manganese(III) acetate. Tetrahedron Lett. 1990, 31, 6371-6374.

33. Nishino, H.; Tategami, S.; Yamada, T.; Korp, J.D.; Kurosawa, K. Formation of 1, 2-dioxanes by the use of tris (2,4-pentanedionato)-manganese (III) or manganese (III) acetate. Bull. Chem. Soc. Jpn. 1991, 64, 1800-1809.

34. Asahi, K.; Nishino, H. Facile endoperoxypropellane synthesis by manganese(III) acetate-mediated aerobic oxidation. Eur. J. Org. Chem. 2008, 2404-2416.

35. Tsubusaki, T.; Nishino, H. Formation of 1,2-dioxolanes using Mn(III)-based reaction of various arylacetylenes with 2,4-pentanedione and related reaction. Tetrahedron 2009, 65, 3745-3752.

36. Haque, M.A.; Nishino, H. Synthesis of peroxylactones using Mn(III)-catalyzed aerobic oxidation. Heterocycles 2011, 83, 1783-1805.

37. Qian, C.-Y.; Nishino, H.; Kurosawa, K. Manganese(II) acetate-mediated double 2hydroperoxyalkylations of barbituric acid and its derivatives. J. Org. Chem. 1993, 58, 4448-4451. 
38. Rahman, M.T.; Nishino, H.; Qian, C.-Y. Synthesis of 4,4-bis(2-hydroperoxyalkyl)pyrazolidine3,5-diones using manganese(III)-catalyzed autoxidation. Tetrahedron Lett. 2003, 44, 5225-5228.

39. Rahman, M.T.; Nishino, H. Manganese(III)-based oxidation of 1,2-disubstituted pyrzolidine-3,5diones in the presence of alkenes. Tetrahedron 2003, 59, 8383-8392.

40. Kumabe, R.; Nishino, H. A unique peroxide formation based on the Mn(III)-catalyzed aerobic oxidation. Tetrahedron Lett. 2004, 45, 703-706.

41. Haque, M.A.; Nishino, H. Synthesis of peroxylactones using Mn(III)-catalyzed aerobic oxidation. Heterocycles 2011, 83, 1783-1805.

42. Rahman, M.T.; Nishino, H. Manganese(III)-catalyzed facile direct hydroperoxidation of some heterocyclic 1,3-dicarbonyl compounds. Org. Lett. 2003, 5, 2887-2890.

43. Fugger, J.; Tien, J.M.; Hunsberger, I.M. The preparation of substituted hydrazines. I. Alkylhydrazines via alkylsydnone. J. Am. Chem. Soc. 1955, 77, 1843-1848.

44. King, J.A.; McMillan, F.H. The preparation of some $\alpha$-benzylamino- $\beta$, $\beta$-dialkoxypropionic acid derivatives. J. Am. Chem. Soc. 1950, 72, 1236-1240.

45. Koech, P.K.; Krische, M.J. Catalytic addition of metallo-aldehyde enolates to ketones: A new C-C bond-forming hydrogenation. Org. Lett. 2004, 6, 691-694.

46. Speziale, A.J.; Jaworski, E.G. N-Substituted glycinate and alaninate esters. J. Org. Chem. 1960, 25, 728-732.

47. Zhu, Y.; Zou, X.; Hu, F.; Yao, C.; Liu, B.; Yang, H. Synthesis and herbicidal evaluation of novel 3-[( $\alpha$-Hydroxy-substituted)benzylidene]pyrrolidine-2,4-diones. J. Agric. Food Chem. 2005, 53, 9566-9570.

48. Chowdhury, F.A.; Nishino, H.; Kurosawa, K. Simple route to azabicyclic peroxides from tetramic acid derivatives using manganese(III)-based molecular oxygen trapping reaction. Heterocycles 1999, 51, 575-591.

49. Jursic, B.S.; Neumann, D.M. Reductive $C$-alkylation of barbituric acid derivatives with carbonyl compounds in the presence of platinum and palladium catalysts. Tetrahedron Lett. 2001, 42, 4103-4107.

50. Detsi, A.; Bardakos, V.; Markopoulos, J.; Igglessi-Markopoulou, O. Reactions of 2-methyl-3,1benzoxazin-4-one with active methylene compounds: A new route to 3-substituted 4-hydroxyquinolin-2(1H)-ones. J. Chem. Soc. Perkin Trans. 1 1996, 2909-2913 and references cited therein.

51. McQuaid, L.A.; Smith, E.C.; Lodge, D.; Pralong, E.; Wikel, J.H.; Calligaro, D.O.; O'Malley, P.J. 3-Phenyl-4-hydroxyquinolin-2(1H)-ones: Potent and selective antagonists at the strychnineinsensitive glycine site on the $N$-methyl-D-aspartate receptor complex. J. Med. Chem. 1992, 35, 3423-3425.

52. Klásek, A.; Mrkvicka, V.; Pevec, A.; Kosmrlj, J. Novel tandem hydration/cyclodehydration of $\alpha$ thiocyanatoketones to 2-oxo-3-thiazolines. Application to thiazolo[5,4-c]quinoline-2,4(3aH,5H)dione Synthesis. J. Org. Chem. 2004, 69, 5646-5651.

53. Ohshima, T.; Sodeoka, M.; Shibasaki, M. Manganese(III)-based oxidative free-radical reaction of $\alpha$-allyl- $\beta$-keto ester with molecular oxygen. Tetrahedron Lett. 1993, 34, 8509-8512.

54. Lamarque, L.; Méou, A.; Brun, P. $\mathrm{Mn}(\mathrm{OAc})_{3}$-promoted hydroxylation of $\alpha$-carbomethoxy- $\gamma$ lactones by molecular oxygen. Can. J. Chem. 2000, 78, 128-132. 
55. Lide, D.R. Handbook of Chemistry and Physics; CRC press: Boca Raton, FL, USA, 1994; pp. $22-23$.

56. Ling, K.-Q.; Lee, Y.; Macikenas, D.; Protasiewicz, J.D.; Sayre, L.M. Copper(II)-mediated autoxidation of tert-butylresorcinols. J. Org. Chem. 2003, 68, 1358-1366 and references cited therein.

57. Bredereck, H.; Bauer, G. Hydroperoxide cyclischer $\beta$-diketone. Justus Liebigs Ann. Chem. 1970, 739, 117-120.

58. Tona, M.; Guardiola, M.; Fajari, L.; Messeguer, A. A study on the mechanism and scope of the radical-mediated oxidation of arylacetoacetates. Tetrahedron 1995, 51, 10041-10052.

59. Nair, V.; Nair, L.G.; Mathew, S. Cerium(IV) mediated oxygenation of dialkyl malonates: A novel synthesis of tartronic acid derivatives. Tetrahedron Lett. 1998, 39, 2801-2804.

60. Neumann, B.; Müller, S.C.; Hauser, M.J.B.; Steinbock, O.; Simoyi, R.H.; Dalal, N.S. Identification and kinetics study of the peroxymalonyl radical in the aerobic oxidation of malonic acid by cerium(IV). J. Am. Chem. Soc. 1995, 117, 6372-6373.

61. Yoshioka, M.; Nishioka, T.; Hasegawa, T. Dye-sensitized photooxidation of 6-acyl- and 6carboalkoxybenzocycloalken-5-ones: Reaction of singlet oxygen with enolic 1,3-dicarbonyl compounds. J. Org. Chem. 1993, 58, 278-281.

62. Christoffers, J.; Wenner, T. Cerium-catalyzed $\alpha$-oxidation of $\beta$-dicarbonyl compounds with molecular oxygen. SynLett 2002, 119-121.

63. Christoffers, J.; Werner, T.; Unger, S.; Frey, W. Preparation of acyloins by cerium-catalyzed, direct hydroxylation of $\beta$-dicarbonyl compounds with molecular oxygen. Eur. J. Org. Chem. 2003, 425-431.

64. Ye, J.-H.; Xue, J.; Ling, K.-Q.; Xu, J.-H. Ceric ammonium nitrate (CAN) mediated novel dimerizations of 4-hydroxyquinolin-2(1H)-ones: The first example of reactions of oxygencentered radicals from 1,3-dicarbonyl compounds. Tetrahedron Lett. 1999, 40, 1365-1368.

65. Hiatt, R.; Irwin, K.C. Homolytic decompositions of hydroperoxides. V. Thermal decompositions. J. Org. Chem. 1968, 33, 1436-1441.

66. Stannett, V.; Mesrobian, R.B. The kinetics of the decomposition of tertiary hydroperoxides in solvents. J. Am. Chem. Soc. 1950, 72, 4125-4130.

67. Boyaci, F.G.; Takaç, S.; Özdamar, T.H. Effects of process parameters on the kinetics of the decomposition of 2-isopropylnaphthalene hydroperoxide into 2-naphthol and acetone. Rev. Chem. Engl. 2000, 16, 249-299.

68. Dannley, R.L.; Jalics, G. The decomposition of silyl hydroperoxides. J. Org. Chem. 1965, 30, 3848-3851.

69. Richardson, W.H. Metal ion decomposition of hydroperoxides. IV. Kinetics and products of copper salt catalyzed decomnposition of $t$-butyl hydroperxide. J. Am. Chem. Soc. 1966, 88, 975-979.

70. Sheldon, R.A.; Kochi, J.K. Metal Catalyzed Oxidations in Organic Chemistry; Academic Press: New York, NY, USA, 1981.

71. Hirano, K.; Sakaguchi, S.; Ishii, Y. Radical addition of ethers to alkenes under dioxygen catalyzed by $N$-hydroxyphthalimide (NHPI)/Co(OAc)2. Tetrahedron Lett. 2002, 43, 3617-3620. 
72. Olah, G.A.; Parker, D.G.; Yoneda, N.; Pelizza, F. Oxyfunctionalization of hydrocarbons. 1. Protolytic cleavage-rearrangement reactions of tertiary alkyl hydroperoxides with magic acid. J. Am. Chem. Soc. 1976, 98, 2245-2250.

73. Andrulis, P.J., Jr.; Dewar, M.J.S.; Dietz, R.; Hunt, R.L. Aromatic oxidation by electron transfer. I. Oxidations of p-methoxytoluene. J. Am. Chem. Soc. 1966, 88, 5473-5478.

74. Heiba, E.I.; Dessau, R.M.; Koehl, W.J., Jr. Oxidation by metal salts. III. Reaction of manganic acetate with aromatic hydrocarbons and the reactivity of the carboxymethyl radical. J. Am. Chem. Soc. 1969, 91, 138-145.

75. Fugger, J.; Tien, J.M.; Hunsberger, I.M. The preparation of substituted hydrazines. I. Alkylhydrazines via alkylsydnone. J. Am. Chem. Soc. 1955, 77, 1843-1848.

76. King, J.A.; McMillan, F.H. The preparation of some $\alpha$-benzylamino- $\beta$, $\beta$-dialkoxypropionic acid derivatives. J. Am. Chem. Soc. 1950, 72, 1236-1240.

77. Koech, P.K.; Krische, M.J. Catalytic addition of metallo-aldehyde enolates to ketones: A new C-C bond-forming hydrogenation. Org. Lett. 2004, 6, 691-694.

78. Speziale, A.J.; Jaworski, E.G. N-Substituted glycinate and alaninate esters. J. Org. Chem. 1960, $25,728-732$.

79. Zhu, Y.; Zou, X.; Hu, F.; Yao, C.; Liu, B.; Yang, H. Synthesis and herbicidal evaluation of novel 3-[( $\alpha$-hydroxy-substituted)benzylidene]pyrrolidine-2,4-diones. J. Agric. Food Chem. 2005, 53, 9566-9570.

80. Lee, V.J.; Branfman, A.R.; Herrin, T.R.; Rinehart, K.L. Synthesis of 3-dienoyl tetramic acids related to streptolydigin and tirandamycin. J. Am. Chem. Soc. 1978, 100, 4225-4236.

81. Mallinger, A.; Nadal, B.; Chopin, N.; Gall, T.L. One-pot synthesis of 3-aryltetramic acids. Eur. J. Org. Chem. 2010, 1142-1148.

82. Nemoto, H.; Kubota, Y.; Yamamoto, Y. Development of a new acyl anion equivalent for the preparation of masked activated esters, and their use to prepare a dipeptide. J. Org. Chem. 1990, $55,4515-4516$.

83. Martínez, R.; Clara-Sosa, A.; Apan, M.T.R. Synthesis and cytotoxic evaluation of new (4,5,6,7tetrahydro-indol-1-yl)-3-R-propionic acids and propionic acid ethyl esters generated by molecular mimicry. Bioorg. Med. Chem. 2007, 15, 3912-3918.

Sample Availability: Samples are available from the authors.

(C) 2011 by the authors; licensee MDPI, Basel, Switzerland. This article is an open-access article distributed under the terms and conditions of the Creative Commons Attribution license (http://creativecommons.org/licenses/by/3.0/). 